\title{
INOVASI BETON KUAT TEKAN AWAL TINGGI YANG MEMADAT SENDIRI MENGGUNAKAN LIMBAH ABU MARMER
}

\author{
Ahmadi \\ Program Studi Teknik Sipil, Fakultas Teknik, Universitas Tunas Pembangunan, Surakarta \\ ahmadimat78@gmail.com \\ Dian Arumningsih DP \\ Program Studi Teknik Sipil, Fakultas Teknik, Universitas Tunas Pembangunan, Surakarta \\ diandindin82@gmail.com
}

\begin{abstract}
Abstrak
Pertumbuhan dan perkembangan infrastruktur di Indonesia terus mengalami peningkatan, sehingga banyak dilakukan penelitian dan pengembangan material konstruksi khususnya beton. Pada dekade terakhir, banyak dilakukan inovasi terhadap beton konvensional agar memiliki kekuatan yang tinggi, awet, murah dan ramah lingkungan serta mudah dalam pengaplikasiannya di lapangan. Penelitian beton ramah lingkungan yaitu pemanfaatan Waste Marble Dust ( limbah pemotongan marmer) dengan gradasi agregat halus dan kasar adalah 60:40. Didapatkan ratio optimum Waste Marble Dust adalah 30\% dari agregat halus. Pengujian chemical element Waste Marble Dust Kalsium Oksida (CaO) adalah unsur kimia terbesar dalam kandungan marmer yaitu 54,02\%. Ratio superplasticizer yang optimum adalah 1,5\% dari semen titius, dan menghasilkan kuat tekan rata-rata $30 \mathrm{MPa}$ pada umur 1 hari. Beton inovasi Waste Marble Dust dapat menghemat Rp.273,362,00/m3 dari harga High Early Strength Concrete memiliki kekuatan $20 \mathrm{MPa}$ pada umur dua hari Strength Concrete tanpa menggunakkan Waste Marble Dust dan telah melewati syarat BS EN 197-1 yang mensyaratkan bahwa High - Early Strength Concrete memiliki kekuatan $30 \mathrm{MPa}$ pada umur dua hari.
\end{abstract}

Kata kunci: Waste Marble Dust, Chemical Element, High Strength Self Compacting Concrete, prosentase optimum.

\begin{abstract}
The growth and development of infrastructure in Indonesia continues to increase, so that a lot of research and development is carried out in construction materials, especially concrete. In the last decade, many innovations have been made to conventional concrete so that it has high strength, durability, is cheap, environmentally friendly and easy to apply in the field. Environmental friendly concrete research, namely the use of Waste Marble Dust (marble cutting waste) with a gradation of fine and coarse aggregates is 60:40. The optimum ratio for Waste Marble Dust is 30\% from fine aggregate. Testing the chemical element Waste Marble Dust Calcium Oxide $(\mathrm{CaO})$ is the largest chemical element in the marble content, namely $54.02 \%$. The optimum superplasticizer ratio is $1.5 \%$ of the titius cement, and produces an average compressive strength of $30 \mathrm{MPa}$ at the age of 1 day. Waste Marble Dust innovation concrete can save Rp. 273,362.00 / m3 from the price High Early Strength Concrete has a strength of $20 \mathrm{MPa}$ at the age of two days Strength Concrete without using Waste Marble Dust and has passed the BS EN 1971 requirements which require that High - Early Strength Concrete has a strength of 30 $\mathrm{MPa}$ at the age of two days.
\end{abstract}

Keywords: Waste Marble Dust, Chemical Element, High Strength Self Compacting Concrete, prosentase optimum. 


\section{PENDAHULUAN}

Pertumbuhan dan perkembangan infrastruktur di Indonesia terus mengalami peningkatan, sehingga banyak dilakukan penelitian dan pengembangan material konstruksi khususnya beton. Pada dekade terakhir, banyak dilakukan inovasi terhadap beton konvensional agar memiliki kekuatan yang tinggi, awet, murah/terjangkau daya beli masyarakat pada umumnya dan ramah lingkungan serta mudah dalam pengaplikasiannya di lapangan. Pada saat ini perkembangan bidang konstruksi diseluruh dunia berkembang begitu pesat dan inovatif, salah satu diantaranya adalah Indonesia, pemerintah dan rakyar Indonesia mengedepankan pembangunan disegala bidang sehingga hamper sebagian besar anggaran belanja Negara terserap dalam laju perkembangan pembangunan Infrastruktur. Maka dari itu dengan mengacu pada SNI2847-2013 yaitu mengenai persyaratan Beton Struktural untuk Bangunan Gedung, kebutuhan tulangan yang diperlukan untuk beton bertulang meningkat dibandingkan dengan persyaratan SNI, sebelumnya dalam praktek di lapangan, semakin meningkat dan beragamnya jumlah tulangan yang ada maka akan mempersulit campuran beton konvensional melewati tulangan- tulangan tersebut, meningkatkan resiko beton tidak mengalami pemadatan yang sempurna, dan membutuhkan waktu yang cukup lama sampai batas pemadatan yang diharapkan.

Untuk mengatasi masalah tersebut dibutuhkan inovasi beton yang dapat memadat sendiri (Self Compacting Concrete) dan kuat tekan beton yang tinggi pada umur awal (HighEarly Strength) sehingga waktu pengerjaan lebih cepat dan menjadi ekonomis serta praktis Pada saat yang sama, inovasi tersebut harus menggunakan konsep sustainable sehingga dapat digunakan secara berkelanjutan dan bisa digunakan untuk generasi ke depannya. Salah satu peneltitian material yang dapat menggunakan konsep sustainable adalah waste marble dust. Dimana upaya untuk memanfaatkan limbah ini adalah sebagai alternatif pengganti agregat halus pada beton.

Waste Marble Dust merupakan hasil limbah dari pemotongan marmer. Menurut Bahar Demirel, pada proses pemotongan marmer, $25 \%$ dari massa awalnya akan hilang melalui proses pemotongan tersebut (Demirel B, 2010). Dengan konsep sustainable, penggunaan limbah waste marble dust akan mengurangi pencemaran lingkungan, dapat menghemat biaya material dan pada saat yang sama penggunaan limbah waste marble dust akan menambah wawasan masyarakat untuk memanfaatkan limbah. Dalam penelitian sebelumnya telah diteliti pengunaan waste marble dust sebagai pengganti semen. Selain itu, penggunaan waste marble dust juga terbukti dapat menghasilkan high early strength concrete yang dapat mempercepat proses konstruksi sehingga dapat terjadi penghematan tenaga kerja dan peralatan serta waktu.

Penggunaan waste marble dust sebagai pengganti semen tidaklah ideal karena meskipun waste marble dust dapat berfungsi sebagai cementitious tetapi penggunaan waste marble dust tidaklah seefektif fly ash dalam hal 
menggantikan portland cement. Oleh karena itu, dalam penelitian ini maka waste marble dust diteliti untuk digunakan sebagai pengganti dari agregat halus.

\section{TINJAUAN PUSTAKA}

\section{A. Beton}

Beton adalah sebuah bahan bangunan komposit yang terbuat dari kombinasi agregat dan pengikat semen. Bentuk paling umum dari beton adalah beton semen Portland, yang terdiri dari agregat mineral (biasanya kerikil dan pasir), semen, dan air. Beton tidak menjadi padat karena air menguap, tetapi semen berhidrasi, mengelem komponen lainnya bersama dan akhirnya membentuk material seperti-batu. Beton digunakan untuk membuat perkerasan jalan, struktur bangunan, fondasi, jembatan penyeberangan, struktur parkiran, dasar untuk pagar/gerbang, dan semen dalam bata atau tembok blok.

\section{B. Beton Ramah Lingkungan}

Beton tersusun atas material semen, pasir, kerikil, dan air, dengan atau tanpa bahan tambah lainnya untuk mencapai performa beton yang diinginkan. Penggunaan semen, walaupun dalam jumlah kecil (sekitar 7\%-15\%), untuk menghasilkan semen digunakan energy yang cukup besar serta menghasilkan limbah tidak sedikit, sehingga yang akan berdampak lingkungan sekitarnya.

\section{Self Compacting Concrete}

Untuk membuat beton yang dapat memadat sendiri Self Compacting Concrete (SCC) yang baik, beton harus memiliki kemampuan untuk berdeformasi yang tinggi, namun juga memiliki ketahanan terhadap segregasi (Okamura \& Ouichi, 2003). Untuk mencapai kondisi tersebut, ada dua hal yang perlu diperhatikan yaitu membatasi jumlah agregat dan campuran harus kental.

\section{Karakteristik Beton SCC}

Berdasarkan spesifikasi SCC dari EFNART, workabilitas kelecekan pada campuran beton segar dapat dikatakan sebagai beton SCC apa bila mempenuhi kriteria sebagai berikut, yaitu:
a) Filling ability
b) Passing Ability
c) Segregation Resistance

\section{E. Bahan Campuran Beton}

Beton merupakan fungsi dari bahan penyusunnya yang terdiri dari bahan semen hidrolik (portland cement), agregat kasar, agregat halus, air dan bahan tambah (admixture atau additive). Untuk mengetahui dan mempelajari perilaku elemen gabungan (bahanbahan penyusun beton), kita memerlukan pengetahuan mengenai karakteristik masingmasing komponen. Proses awal terbentuknya beton adalah pasta semen yaitu proses hidrasi antara air dengan semen, selanjutnya jika ditambahkan dengan agregat halus menjadi mortar dan jika ditambahkan dengan agregat kasar menjadi beton. (Tri Mulyono, 2004).

Perbandingan dari unsur-unsur tersebut akan menjadi hal terpenting dari kekuatan beton, sehingga diperlukan perancangan yang tepat sehingga diperoleh perbandingan yang sesuai 
dengan spesifikasi dalam mencapai kekuatan yang direncanakan.

Tabel 1. Perbandingan unsur beton

\begin{tabular}{|c|c|}
\hline Agregat (kasar + halus) & $60 \%-80 \%$ \\
\hline Semen & $7 \%-15 \%$ \\
\hline Air & $14 \%-21 \%$ \\
\hline Udara & $1 \%-8 \%$ \\
\hline
\end{tabular}

\section{F. Semen}

Karena beton terbuat dari agregat yang diikat bersama oleh pasta semen yang mengeras maka kualitas semen sangat mempengaruhi kualitas beton. Pasta semen adalah lem, apabila semakin tebal tentu semakin kuat. Namun jika terlalu tebal juga tidak menjamin lekatan yang baik. Semen adalah bahan yang mempunyai sifat adhesif maupun kohesif, yaitu bahan pengikat. Menurut Standar Industri Indonesia, SNI 00121981, definisi semen portland adalah semen hidraulis yang dihasilkan dengan cara menghaluskan klinker yang terutama terdiri dari silikat-silikat kalsium yang bersifat hidraulis bersama bahan-bahan yang biasa digunakan, yaitu gypsum.

\section{G. Agregat}

Mengingat bahwa agregat menempati $70-75 \%$ dari total volume beton maka kualitas agregat sangat berpengaruh terhadap kualitas beton. Dengan agregat yang baik, beton dapat dikerjakan (workable), kuat, tahan lama (durable) dan ekonomis,

\section{H. Air}

Semen tidak bisa menjadi pasta tanpa air. Air harus selalu ada didalam beton cair, tidak saja untuk hidrasi semen, tetapi juga untuk mengubahnya menjadi suatu pasta sehingga betonnya lecak (workable). Jumlah air yang terikat dalam beton dengan faktor air-semen 0.65 adalah sekitar $20 \%$ dari berat semen pada umur 4 minggu. Dihitung dari komposisi material semen. Jumlah air yang diperlukan untuk hidrasi secara teoritis adalah $35-37 \%$ dari berat semen (Nugraha P, 2007).

\section{Superplasticizer (Sika Visconcrete 1003)}

Superplasticizer yang digunakan adalah sika visconcrete 1003, Sika Visconcrete-1003 adalah superplasticiser generasi ketiga untuk beton dan mortar. Terutama dikembangkan untuk produksi beton aliran tinggi dengan sifat retensi aliran yang luar biasa dan signifikan pengurangan bleding dan segregasi.

\section{J. Waste Marble Dust}

Waste Marble Dust adalah limbah pemotongan marmer yang terpakai, banyak penelitian yang menggunakan Waste Marble Dust (WMD) sebagai pengganti semen karena kemampuannya untuk mengikat (Ergun A, 2010). Tetapi, semua penelitian yang telah dilakukan menyatakan bahwa Waste Marble Dust menurunkan kekuatan pada umur akhir karena pengenceran terhadap $\mathrm{C}_{2} \mathrm{~S}$ dan $\mathrm{C}_{3} \mathrm{~S}$ (Turker et al, 2002). Berbeda dengan penelitian dimana Waste Marble Dust digunakan sebagai pengganti agregat halus dan kasar, ditemukan bahwa Waste Marble Dust memiliki banyak keuntungan seperti menurunkan porositas, menambah workability dan meningkatkan kekuatan umur awal (Demirel B, 2010). 


\section{K. Rational Mix Design}

Untuk membuat campuran Self Compacting Concrete yang baik, metode mix design yang biasa tidak lagi dapat dipergunakan. Karena itu pada tahun 1995 Okamura dan Ozawa mengusulkan metode mix design yang sederhana dengan mengacu pada material yang sudah tersedia pada pabrik beton ready mix. Pemadatan mandiri dapat didapatkan dengan mengatur faktor air binder dan dosis superplasticizer saja.

\section{Pengujian Kuat Tekan Beton}

Kuat tekan beton adalah kemampuan beton dalam menerima beban tiap satuan luas. Kuat tekan beton mengidentifikasikan mutu dari sebuah struktur. Semakin tinggi kekuatan struktur yang dikehendaki maka semakin tinggi pula mutu beton yang dihasilkan (Mulyono, 2004). Pengujian nilai kuat tekan beton, beton dilakukan di laboratorium dengan menggunakan benda uji silinder dengan diameter $150 \mathrm{~mm}$ dan tinggi $300 \mathrm{~mm}$.Rumus untuk mendapatkan nilai kuat tekan beton berdasarkan percobaan dilaboratorium sebagai berikut :

$$
f^{\prime} c=\frac{\boldsymbol{P}}{\boldsymbol{A}}
$$

\section{Keterangan:}

$$
\begin{aligned}
& f^{\prime}{ }_{\mathrm{c}}=\text { Kuat tekan beton }(\mathrm{MPa}) \\
& \mathrm{P}=\text { Beban tekan }(\mathrm{N}) \\
& \mathrm{A}=\text { Luas penampang benda uji }
\end{aligned}
$$

\section{METODE PENELITIAN}

\section{A. Metode Penelitian Dan Pengumpulan Data}

Penelitian Tugas Akhir ini akan menganalisis secara langsung dan objektif dengan tujuan menghasilkan suatu analisa mengenai High Early Strength Self Compacting Concrete berbahan dasar Waste Marble Dust. Teknik pengumpulan data dalam penelitian ini adalah dengan menggunakan studi pustaka dan penelitian eksperimen di laboratorium. Teknik ini bertujuan untuk mencari data-data yang relevan dengan jenis penelitian yang akan dilaksanakan. Selain itu, data yang didapat dari studi pustaka akan membantu bagi penulis agar dapat memperluas wawasan dan menyelesaikan penelitian. Setelah melakukan studi pustaka mengenai High Early Strength Self Compacting Concrete maka penelitian dilanjutkan dengan penilitian eksperimen material yaitu Waste Marble Dust sebagai pengganti agregat halus di laboratorium. Penelitian dilanjutkan dengan menguji kebersihan pasir, pengujian kimia, menghitung Gravity Spesific material, dan Sieve Analysis. Beberapa mix design dibuat dan diuji untuk mengetahui w/c optimum dan kadar Waste Marble Dust optimum agar mencapai kuat tekan dan flow beton yang optimum. Pengujian ini dilakukan dengan menggunakan sampel silinder berukuran $30 \times 15 \mathrm{~cm}$. Lalu hasil pengujian slump dan kekuatan satu harinya dilakukan analisa, serta tak lupa untuk memberikan kesimpulan dan saran.

\section{B. Waktu dan Tempat Pelaksanaan}

Waktu pelaksanaan penelitian ini dimulai pada 1 Oktober 2019 sampai dengan 1 Maret 2019. Tempat pelaksanaan dari penelitian ini yaitu di Laboratorium Bahan Fakultas Teknik Sipil Universitas Tunas Pembangunan Surakarta 


\section{Alat-Alat Yang Digunakan}

Instrumen pelaksanaan dalam penelitian ini yaitu:
a. Satu set saringan
b. Timbangan
c. Oven
d. Piknometer
e. Kerucut Abrams
f. Cetakan silinder
g. Mesin pengaduk beton (Concrete Mixer)
h. Mesin uji tekan g. Alat bantu

\section{Pemilihan Material}

Material yang digunakan dalam pembuatan beton ini adalah sebagai berikut :
a. Semen
b. Agregat Halus
c. Agregat Kasar
d. Waste Marble dust
e. Air
f. Sika Visconcrete 1003

\section{E. Pengujian Material}

Sebelum melaksanakan mix design terlebih dahulu melakukan pengujian agregat baik agregat halus maupun kasar yang terdiri dari:

a. Pengujian Agregat Halus Pengujian agregat halus meliputi:

1) Kadar lumpur : Untuk mengetahui besarnya kandungan lumpur dalam pasir.

2) Kadar zat organik : Untuk menentukan banyak sedikitnya kandungan zat organik pada dalam pasir.
3) Specific gravity : Untuk menentukan berat jenis, berat jenis SSD, dan penyerapan air agregat halus.

4) Gradasi : Untuk menentukan nilai modulus kehalusan agregat halus.

b. Pengujian Agregat Kasar Pengujian agregat halus meliputi:

1) Kadar lumpur : Untuk mengetahui besarnyakandungan lumpur dalam kerikil.

2) Specific gravity: Untuk menentukan berat jenis, berat jenis SSD, dan penyerapan air agregat kasar.

3) Gradasi : Untuk memeriksa variasi susunan agregat dan nilai modulus kehalusan agregat kasar.

4) Abrasi

F. Metode Pembuatan Beton

a. Mempersiapkan Bahan-Bahan

b. Membersihkan Pasir dan Kerikil

c. Membuat Pasir dan Kerikil dalam Keadaan

d. Saturated Surface Dry

e. Mengukur dan menimbang setiap material yang dipakai (Pasir, kerikil, semen, waste marble dust, air dan superplasticizer) dari total Water Content dimasukkan terlebih dahulu dan diaduk sampai merata lalu $30 \%$ sisa air dimasukan.

f. Campuran beton di slump flow test untuk mengetahui apakah workabilitas sudah terpenuhi

g. Slump flow test campuran beton sudah memenuhi standar EFNARC. Kemudian di cetak ke dalam bekisting. 


\section{G. Metode Pembuatan Beton}

h. Mempersiapkan Bahan-Bahan

i. Membersihkan Pasir dan Kerikil

j. Membuat Pasir dan Kerikil dalam Keadaan

k. Saturated Surface Dry

1. Mengukur dan menimbang setiap material yang dipakai (Pasir, kerikil, semen, waste marble dust, air dan superplasticizer) dari total Water Content dimasukkan terlebih dahulu dan diaduk sampai merata lalu $30 \%$ sisa air dimasukan.

m. Campuran beton di slump flow test untuk mengetahui apakah workabilitas sudah terpenuhi

Tabel 2 Hasil Percobaan Mix Design n. Slump flow test campuran beton sudah memenuhi standar EFNARC. Kemudian di cetak ke dalam bekisting.

\section{HASIL DAN PEMBAHASAN}

A. Hasil Percobaan Mix Design

Tujuan dari pembuatan Mix Design adalah untuk mengetahui perbandingan bahanbahan yang akan digunakan dalam pembuatan beton, agar menghasilkan beton dengan kuat tekan dan sifat-sifat lain yang diharapkan. Adapun hasil mix design di tunjukkan pada table sebagai berikut :

\section{PERENCANAAN MIX DESIGN SCC INOVASI BETON SCC WMD}

\begin{tabular}{|c|c|c|c|c|c|c|c|}
\hline \multicolumn{2}{|c|}{ Nama } & $=$ & $\begin{array}{l}\text { 1. Ahmadi } \\
\text { 2.Dian ADP }\end{array}$ & \multicolumn{2}{|c|}{$\begin{array}{c}\text { Tanggal } \\
\text { Slump }\end{array}$} & \multicolumn{2}{|r|}{ 13-Nov-19 } \\
\hline \multicolumn{2}{|c|}{ Nama Beton } & $=$ & SCC WMD & \multicolumn{2}{|c|}{ Flow } & $=$ & $60-80 \mathrm{~cm}$ \\
\hline & $\mathrm{F}^{\prime} \mathrm{c}$ & $=$ & 30 Mpa 1 hari & \multicolumn{2}{|c|}{ Inovasi } & $=$ & WMD \\
\hline $\mathbf{A}$ & Berat Jenis & & & & & & \\
\hline 1 & Bj. Pasir & $=$ & 2600 & & & & \\
\hline 2 & Bj. Split & $=$ & 2650 & & & & \\
\hline 3 & Bj. WMD & $=$ & 2300 & & & & \\
\hline 4 & Bj. Air & $=$ & 1000 & & & & \\
\hline 5 & Bj. Semen & $=$ & 3150 & & & & \\
\hline B & Material & & & & & & \\
\hline 1 & Semen & $=$ & 400 & & & & \\
\hline 2 & Fas & $=$ & 0,31 & $\mathrm{x}$ & 400 & $=$ & 124 \\
\hline 3 & SP & $=$ & $1 \%$ & $\mathrm{x}$ & 400 & $=$ & 4 \\
\hline 4 & Udara & $=$ & $1 \%$ & & & & \\
\hline C & Kebutuhan & & & & & & \\
\hline 1 & Semen & $=$ & 400 & $:$ & 3150 & $=$ & 0,127 \\
\hline 2 & Fas & $=$ & 124 & $:$ & 1000 & $=$ & 0,124 \\
\hline 3 & Udara & $=$ & $1 \%$ & & & $=$ & 0,01 \\
\hline & $1 \mathrm{~m} 3$ & $=$ & 0,127 & + & 0,124 & + & 0,01 \\
\hline & & $=$ & 0,261 & - & 1 & & \\
\hline & & $=$ & 0,739 & & & & \\
\hline & Agg Halus & $=$ & $45 \%$ & & & & \\
\hline & - Pasir & $=$ & $70 \%$ & $\mathrm{x}$ & $45 \%$ & & \\
\hline & & $=$ & $31,5 \%$ & & & & \\
\hline & & $=$ & $31,5 \%$ & $\mathrm{x}$ & 0,739 & $\mathrm{x}$ & 2600 \\
\hline & & $=$ & 605,25 & & & & \\
\hline
\end{tabular}




$\begin{array}{lllllll}- \text { WMD } & = & 30 \% & \text { x } & 45 \% & & \\ & = & 13,5 \% & & & & 2300 \\ & = & 13,5 \% & \text { x } & 0,739 & \text { x } & \\ & = & 229,46 & & & & 2650 \\ \text { Agg.Kasar } & = & 55 \% & \text { X } & & & \\ - \text { Split } & = & 55 \% & \text { X } & 0,739 & \text { x } & \\ \text { D Kesimpulan } & & 1077,12 & & & & \end{array}$

\begin{tabular}{|c|c|c|c|c|}
\hline \multirow{2}{*}{ No } & \multirow{2}{*}{ Material } & \multicolumn{2}{|c|}{ Volume } & \multirow{2}{*}{$\begin{array}{c}\text { SF } \\
1,2 \\
\end{array}$} \\
\hline & & $1 \mathrm{~m} 3$ & 0,0052 & \\
\hline 1 & Semen & 400 & 2,08 & 2,496 \\
\hline 2 & Air & 124,000 & 0,6448 & 0,774 \\
\hline 3 & Pasir & 605,25 & 3,15 & 3,777 \\
\hline 4 & WMD & 229,46 & 1,19 & 1,432 \\
\hline 5 & Split & 1077,12 & 5,60 & 6,721 \\
\hline 6 & $\mathrm{Sp}$ & 4 & 0,02 & 0,025 \\
\hline
\end{tabular}

\section{Keterangan; Perhitungan Mix Design Inovasi}

Penggunaan semen beton self compacting concrete using waste marble dust, kadar semen yang digunakan adalah $450 \mathrm{~kg} / \mathrm{m} 3$. Optimisasi agregat dilakukan dengan meninjau Journal Prof. Okamura dan Ouichi, dimana agregat kasar tidak boleh melebihi $2 \mathrm{~cm}$ dan agregat halus lebih banyak dibandingkan agregat kasar mix design final menggunakan mix design. Perbandingan volume agregat kasar dan agregat halus adalah 40:60, perencanaan mix design dengan penggunakan inovasi harus dilakukan trial and error untuk mendapatkan hasil yang optimal.

\section{KESIMPULAN/RINGKASAN}

1. Berdasarkan penelitian yang telah dilakukan, Waste Marble Dust dapat digunakan sebagai pengganti agregat halus.

2. Penelitian yang telah dilakukan Waste Marble Dust terdapat kandungan kimia Kalsium Oksida $(\mathrm{CaO})$ adalah unsur kimia terbesar dalam kandungan marmer, yaitu $54,02 \%$.

3. Pengaruh Waste Marble Dust yaitu tidak terjadi penurunan kekuatan dan bahkan meningkatkan workability jika dibandingkan dengan beton tanpa Waste Marble Dust.

4. Kadar optimal yang dapat digantikan oleh Waste Marble Dust adalah 30\% dari volume agregat halus. Penggunaan kadar optimal tersebut dapat dibandingkan melalui peningkatan kekuatan dimana 30\% meningkatkan kekuatan dengan signifikan dan mengurangi workabilitas minimal.

5. Pemakaian dalam jumlah besar mengurangi produksi semen, sehingga mengurangi gas rumahkaca yang dihasilkan dari produksi semen.

6. Dengan menggunakan Waste Marble Dust, bisa dilihat bahwa penghematan Innovation Eco-Friendly Self Compacting Concrete dengan Waste Marble Dust dibandingkan tanpa Waste Marble Dust sebesar Rp. 273,362,00/m3. 


\section{DAFTAR PUSTAKA}

ACI Committee 211.1993. Guide for Selecting Proportions for Normal Heavyweight, and Mass Concrete (ACI 211.1-91). American Concrete Institute. Detroit Michigan

ACI Committee 234.1994. Guide to Durable Concrete (ACI Manual of Concrete Practise) Part I.American Concrete Institute. Detroit Michigan

Neville, A.M., Brooks, J.J,1987.Concrete Technology.New York:Longman Scientific \& Technical.

Mulyono, Tri (2004)

Teknologi Beton. Penerbit Andi. Yogyakarta.

Paramita, A., Soebandono, B., Faizah, R.2016. Studi Komparasi Perancangan Struktur Gedung Berdasarkan SNI $03-2847$ 2002 dan SNI 2847: 2013 dengan SNI 03 - 1726 2012. Yogyakarta: Universitas Muhammadiyah Yogyakarta. Paul Nugroho, Antoni. 2007. Teknologi Beton. CV. Andi Offset, Yogyakarta.

Sugiharto, Handoko. Penelitian Mengenai Peningkatan Kekuatan Awal Beton Pada Self Compacting Concrete. Universitas Kristen Petra.

Topçu, I.B, Bilir, T., Uygunog lu, T., (2008). Effect of waste marble dust content as filler on properties of self-compacting concrete, Turkey: Eskisehir Osmangazi University \& Afyon Kocatepe University.

Demirel, B.2010.The effect of the using waste marble dust as fine sand on the mechanical properties of the concrete. Turkey: Firat University. 